Research Article

\title{
Strong Convergence Theorems for a Countable Family of Total Quasi- $\phi$-Asymptotically Nonexpansive Nonself Mappings
}

\author{
Liang-cai Zhao' ${ }^{1}$ and Shih-sen Chang ${ }^{2}$ \\ ${ }^{1}$ College of Mathematics, Yibin University, Yibin 644000, China \\ ${ }^{2}$ College of Statistics and Mathematics, Yunnan University of Finance and Economics, Yunnan, \\ Kunming 650221, China
}

Correspondence should be addressed to Shih-sen Chang, changss@yahoo.cn

Received 3 June 2012; Revised 22 July 2012; Accepted 23 July 2012

Academic Editor: Naseer Shahzad

Copyright (C) 2012 L.-c. Zhao and S.-s. Chang. This is an open access article distributed under the Creative Commons Attribution License, which permits unrestricted use, distribution, and reproduction in any medium, provided the original work is properly cited.

The purpose of this paper is to introduce a class of total quasi- $\phi$-asymptotically nonexpansivenonself mappings and to study the strong convergence under a limit condition only in the framework of Banach spaces. As an application, we utilize our results to study the approximation problem of solution to a system of equilibrium problems. The results presented in the paper extend and improve the corresponding results announced by some authors recently.

\section{Introduction}

Throughout this paper, we assume that $E$ is a real Banach space, $C$ is a nonempty closed and convex subset of $E, E^{*}$ is the dual space of $E$, and $J: E \rightarrow 2^{E^{*}}$ is the normalized duality mapping defined by

$$
J(x)=\left\{f^{*} \in E^{*},\left\langle x, f^{*}\right\rangle=\|x\|^{2}=\|f\|^{2}\right\}, \quad x \in E .
$$

Recall that a Banach space $E$ is said to be strictly convex if $\|x+y\| / 2<1$ for all $x, y \in$ $U=\{z \in E:\|z\|=1\}$ with $x \neq y$. E is said to be uniformly convex, if for each $\epsilon \in(0,2]$, there exists $\delta>0$ such that $\|x+y\| / 2<1-\delta$ for all $x, y \in U$ with $\|x-y\| \geq \epsilon$. E is said to be smooth, if the limit

$$
\lim _{t \rightarrow 0} \frac{\|x+t y\|-\|x\|}{t}
$$


exists for all $x, y \in U$. And $E$ is said to be uniformly smooth, if the above limit is exists uniformly for $x, y \in U$.

In the sequel, we shall denote the fixed point set of a mapping $T$ by $F(T)$. When $\left\{x_{n}\right\}$ is a sequence in $E$, then $x_{n} \rightarrow x\left(x_{n}-x\right)$ will denote strong (weak) convergence of the sequence $\left\{x_{n}\right\}$ to $x$.

A mapping $T: C \rightarrow C$ is said to be nonexpansive, if

$$
\|T x-T y\| \leq\|x-y\|, \quad \forall x, y \in C .
$$

A mapping $T: C \rightarrow C$ is said to be asymptotically nonexpansive if there exists a sequence $\left\{k_{n}\right\} \subset[1, \infty)$ such that

$$
\left\|T^{n} x-T^{n} y\right\| \leq k_{n}\|x-y\|, \quad \forall x, y \in C .
$$

Recall that a subset $C$ of $E$ is said to be retract of $E$, if there exists a continuous mapping $P: E \rightarrow C$ such that $P x=x$, for all $x \in C$.

It is well known that every nonempty closed and convex subset of a uniformly convex Banach space is a retract of $E$. A mapping $P: E \rightarrow C$ is said to be a retraction, if $P^{2}=P$. It follows that if a mapping $P$ is a retraction, then $P y=y$ for all $y$ in the range of $P$. A mapping $P: E \rightarrow C$ is said to be a nonexpansive retraction, if it is nonexpansive and it is a retraction from $E$ to $C$.

In the sequel, we assume that $E$ is a smooth, strictly convex, and reflexive Banach space and $C$ is a nonempty closed convex subset of $E$. Throughout this paper we assume that $\phi: E \times E \rightarrow \mathcal{R}^{+}$is the Lyapunov function which is defined by

$$
\phi(x, y)=\|x\|-2\langle x, J y\rangle+\|y\|^{2}, \quad \forall x, y \in E
$$

It is obvious from the definition of $\phi$ that

$$
\begin{gathered}
(\|x\|-\|y\|)^{2} \leq \phi(x, y) \leq(\|x\|+\|y\|)^{2}, \quad \forall x, y \in E \\
\phi\left(x, J^{-1}(\lambda J y+(1-\lambda) J z)\right) \leq \lambda \phi(x, y)+(1-\lambda) \phi(x, z), \quad \forall x, y \in E .
\end{gathered}
$$

Following Alber [1], the generalized projection $\Pi_{C}: E \rightarrow C$ is defined by

$$
\Pi_{C}(x)=\arg \inf _{y \in C} \phi(y, x), \quad \forall x \in E
$$

Lemma 1.1 (see [1]). Let E be a smooth, strictly convex, and reflexive Banach space and $C$ be a nonempty closed convex subset of $E$. Then the following conclusions hold:

(1) $\phi\left(x, \Pi_{C} y\right)+\phi\left(\Pi_{c} y, y\right) \leq \phi(x, y)$ for all $x \in C$ and $y \in E$;

(2) If $x \in E$ and $z \in C$, then $z=\Pi_{C} x \Leftrightarrow\langle z-y, J x-J z\rangle \geq 0$, for all $y \in C$;

(3) For $x, y \in E, \phi(x, y)=0$ if and only if $x=y$. 
Remark 1.2. If $E$ is a real Hilbert space $H$, then $\phi(x, y)=\|x-y\|^{2}$ and $\Pi_{C}=P_{C}$ (the metric projection of $H$ onto $C)$.

A mapping $T: C \rightarrow C$ is said to be closed, if for any sequence $\left\{x_{n}\right\} \subset C$ with $x_{n} \rightarrow x$ and $T x_{n} \rightarrow y$, then $T x=y$.

Definition 1.3. Let $P: E \rightarrow C$ be the nonexpansive retraction.

(1) $T: C \rightarrow E$ is said to be quasi- $\phi$-nonexpansive nonself mapping, if $F(T) \neq \emptyset$ and

$$
\phi(u, T x) \leq \phi(u, x), \quad \forall x \in C, u \in F(T)
$$

(2) $T: C \rightarrow E$ is said to be quasi- $\phi$-asymptotically nonexpansive nonself mapping, if $F(T) \neq \emptyset$ and there exists a real sequence $\left\{k_{n}\right\} \subset[1, \infty)$ with $k_{n} \rightarrow 1$ such that

$$
\phi\left(u, T(P T)^{n-1} x\right) \leq k_{n} \phi(u, x), \quad \forall x \in C, u \in F(T), n \geq 1 .
$$

(3) $T: C \rightarrow E$ is said to be total quasi- $\phi$-asymptotically nonexpansive nonself mapping, if $F(T) \neq \emptyset$ and there exists nonnegative real sequence $\left\{v_{n}\right\},\left\{\mu_{n}\right\}$ with $v_{n} \rightarrow 0, \mu_{n} \rightarrow$ 0 (as $n \rightarrow \infty)$ and a strictly increasing continuous function $\rho: \mathcal{R}^{+} \rightarrow \mathcal{R}^{+}$with $\rho(0)=0$ such that for all $x \in C, u \in F(T)$

$$
\phi\left(u, T(P T)^{n-1} x\right) \leq \phi(u, x)+v_{n} \rho(\phi(u, x))+\mu_{n}, \quad \forall n \geq 1
$$

(4) A countable family of nonself mappings $\left\{T_{i}\right\}: C \rightarrow E$ is said to be uniformly total quasi- $\phi$-asymptotically nonexpansive, if $\bigcap_{i=1}^{\infty} F\left(T_{i}\right) \neq \emptyset$ and there exists nonnegative real sequence $\left\{v_{n}\right\},\left\{\mu_{n}\right\}$ with $v_{n} \rightarrow 0, \mu_{n} \rightarrow 0$ (as $n \rightarrow \infty$ ) and a strictly increasing continuous function $\rho: \mathcal{R}^{+} \rightarrow \mathcal{R}^{+}$with $\rho(0)=0$ such that for each $i \geq 1$ and all $x \in C, u \in \bigcap_{i=1}^{\infty} F\left(T_{i}\right)$

$$
\phi\left(u, T_{i}\left(P T_{i}\right)^{n-1} x\right) \leq \phi(u, x)+v_{n} \rho(\phi(u, x))+\mu_{n}, \quad \forall n \geq 1 .
$$

Remark 1.4. From the definitions, it is easy to know that

(1) If $T$ is a quasi- $\phi$-nonexpansive nonself mapping, then it must be a quasi- $\phi$ asymptotically nonexpansive nonself mapping with $\left\{k_{n}=1\right\}$.

(2) Taking $\rho(t)=t, t>0, v_{n}=\left(k_{n}-1\right)$ and $\mu_{n}=0$, then (1.9) can be rewritten as

$$
\phi\left(u, T(P T)^{n-1} x\right) \leq \phi(u, x)+v_{n} \rho(\phi(u, x))+\mu_{n}, \quad \forall n \geq 1, x \in C, u \in F(T) .
$$

This implies that each quasi- $\phi$-asymptotically nonexpansive nonself mapping must be a total quasi- $\phi$-asymptotically nonexpansive nonself mapping, but the converse is not true. 
A nonself mapping $T: C \rightarrow E$ is said to be uniformly L-Lipschitz continuous, if there exists a constant $L>0$ such that

$$
\left\|T(P T)^{n-1} x-T(P T)^{n-1} y\right\| \leq L\|x-y\|, \quad \forall x, y \in C, n \geq 1 .
$$

Lemma 1.5 (see [2]). Let E be a smooth and uniformly convex Banach space and let $\left\{x_{n}\right\},\left\{y_{n}\right\}$ be two sequences of $E$. If $\phi\left(x_{n}, y_{n}\right) \rightarrow 0($ as $n \rightarrow \infty)$ and either $\left\{x_{n}\right\}$ or $\left\{y_{n}\right\}$ is bounded, then $\left\|x_{n}-y_{n}\right\| \rightarrow 0$ (as $\left.n \rightarrow \infty\right)$.

Lemma 1.6. Let $E$ be a smooth, strictly convex, and reflexive Banach space and $C$ be a nonempty closed and convex subset $E$. Let $T: C \rightarrow E$ be a closed and total quasi- $\phi$-asymptotically nonexpansive nonself mapping with nonnegative real sequence $\left\{v_{n}\right\},\left\{\mu_{n}\right\}$ and a strictly increasing continuous function $\rho: R^{+} \rightarrow \mathcal{R}^{+}$such that $v_{n} \rightarrow 0, \mu_{n} \rightarrow 0$ and $\rho(0)=0$. Then the fixed point set $F(T)$ is a closed and convex subset of $C$.

Proof. Let $\left\{x_{n}\right\}$ be a sequence in $F(T)$ such that $x_{n} \rightarrow u($ as $n \rightarrow \infty)$. Since $T x_{n}=x_{n} \rightarrow u$, by the closeness of $T$, we have $u=T u$, that is, $u \in F(T)$. This shows that $F(T)$ is a closed set in $C$.

Next, we prove that $F(T)$ is convex. For any $x, y \in F(T), t \in(0,1)$, putting $q=t x+(1-$ t) $y$, we prove that $q \in F(T)$. Indeed, let $\left\{u_{n}\right\}$ be a sequence generated by

$$
\begin{aligned}
& u_{1}=T q, \quad u_{2}=T P T q=T P u_{1}, \quad u_{3}=T(P T)^{2} q=T P u_{2}, \ldots \\
& u_{n}=T(P T)^{n-1} q=T P u_{n-1}, \ldots
\end{aligned}
$$

we have

$$
\begin{aligned}
\phi\left(q, u_{n}\right) & =\|q\|^{2}-2\left\langle q, J u_{n}\right\rangle+\left\|u_{n}\right\|^{2} \\
& =\|q\|^{2}-2 t\left\langle x, J u_{n}\right\rangle-2(1-t)\left\langle y, J u_{n}\right\rangle+\left\|u_{n}\right\|^{2} \\
& =\|q\|^{2}+t \phi\left(x, u_{n}\right)+(1-t) \phi\left(y, u_{n}\right)-t\|x\|^{2}-(1-t)\|y\|^{2}
\end{aligned}
$$

Since

$$
\begin{aligned}
& t \phi\left(x, u_{n}\right)+(1-t) \phi\left(y, u_{n}\right) \\
& \leq t\left(\phi(x, q)+v_{n} \rho(\phi(x, q))+\mu_{n}\right)+(1-t)\left(\phi(y, q)+v_{n} \rho(\phi(y, q))+\mu_{n}\right) \\
&= t\left(\|x\|^{2}-2\langle x, J q\rangle+\|q\|^{2}+v_{n} \rho(\phi(x, q))+\mu_{n}\right) \\
&+(1-t)\left(\|y\|^{2}-2\langle y, J q\rangle+\|q\|^{2}+v_{n} \rho(\phi(y, q))+\mu_{n}\right) \\
&= t\|x\|^{2}+(1-t)\|y\|^{2}-\|q\|^{2}+t v_{n} \rho(\phi(x, q))+(1-t) v_{n} \rho(\phi(y, q))+\mu_{n} .
\end{aligned}
$$

Substituting (1.16) into (1.15), and simplifying we have

$$
\phi\left(q, u_{n}\right) \leq t v_{n} \rho(\phi(x, q))+(1-t) v_{n} \rho(\phi(y, q))+\mu_{n} \longrightarrow 0 \quad(n \longrightarrow \infty) .
$$

By Lemma 1.5, we have $u_{n} \rightarrow q(n \rightarrow \infty)$. This implies that $u_{n+1} \rightarrow q(n \rightarrow \infty)$. 
Since $u_{n+1}=T(P T)^{n} q=T P T(P T)^{n-1} q=T P u_{n}$ and $T$ is closed, we have $q=T P q$. Since $q \in C, P q=q$, thus $q=T q$. this implies that $F(T)$ is a convex set in $C$.

Concerning the strong and weak convergence of asymptotically nonexpansive self or nonself mappings, relatively nonexpansive, quasi- $\phi$-nonexpansive and quasi- $\phi$ asymptotically nonexpansive self or nonself mappings have been considered extensively by several authors in the setting of Hilbert or Banach spaces (see e.g., [2-19]).

The purpose of this paper is to modify the Halpern and Mann-type iteration algorithm for a family of of total quasi- $\phi$-asymptotically nonexpansive nonself mappings and to have the strong convergence under removing $F(T)$ is a convex set of condition and a limit condition only in the framework of Banach spaces. As an application, we utilize our results to study the approximation problem of solution to a system of equilibrium problems. The results presented in the paper extend and improve the corresponding results of Chang et al. [4-7], W. P. Guo and W. Guo [8], Hao et al. [9], Kamimura and Takahashi [10], Kiziltunc and Temir [11], Nilsrakoo and Saejung [2], Pathak et al. [12], Qin et al. [13], Su et al. [14], Thianwan [15], Wang et al. [16], Yıldırım and Özdemir [17], Yang and Xie [18], Zegeye et al. [19], Kanjanasamranwong et al. [20], Saewan and Kumam [21-24] and Wattanawitoon and Kumam [25].

\section{Main Results}

Theorem 2.1. Let $E$ be a real uniformly convex and uniformly smooth Banach space, and $C$ be a nonempty closed convex subset $E$. Let $T_{i}: C \rightarrow E, i=1,2, \ldots$ be a family of closed and uniformly total quasi- $\phi$-asymptotically nonexpansive nonself mappings with nonnegative real sequence $\left\{v_{n}\right\},\left\{\mu_{n}\right\}$ and a strictly increasing continuous function $\rho: R^{+} \rightarrow R^{+}$such that $v_{n} \rightarrow 0, \mu_{n} \rightarrow 0$ and $\rho(0)=0$, and for each $i \geq 1, T_{i}$ be uniformly $L_{i}$-Lipschitz continuous. Let $\left\{\alpha_{n}\right\}$ be a sequence in $[0,1]$ and $\left\{\beta_{n}\right\}$ be a sequence in $(0,1)$ satisfying the following conditions:

(a) $\lim _{n \rightarrow \infty} \alpha_{n}=0$;

(b) $0<\liminf \operatorname{in}_{n \rightarrow \infty} \beta_{n} \leq \lim \sup _{n \rightarrow \infty} \beta_{n}<1$.

Let $\left\{x_{n}\right\}$ be a sequence generated by

$$
\begin{gathered}
x_{1} \in E \text { chosen arbitrarily; } C_{1}=C, \\
y_{n, i}=J^{-1}\left[\alpha_{n} J x_{1}+\left(1-\alpha_{n}\right)\left(\beta_{n} J x_{n}+\left(1-\beta_{n}\right) J T_{i}\left(P T_{i}\right)^{n-1} x_{n}\right)\right], \quad i \geq 1, \\
C_{n+1}=\left\{z \in C_{n}: \sup _{i \geq 1} \phi\left(z, y_{n, i}\right) \leq \alpha_{n} \phi\left(z, x_{1}\right)+\left(1-\alpha_{n}\right) \phi\left(z, x_{n}\right)+\theta_{n}\right\}, \\
x_{n+1}=\prod_{C_{n+1}} x_{1}, \quad \forall n \geq 1 .
\end{gathered}
$$

where $\theta_{n}=v_{n} \sup _{u \in \mathcal{F}} \rho\left(\phi\left(u, x_{n}\right)\right)+\mu_{n}$, for all $n \geq 1, \mathcal{F}:=\bigcap_{i=1}^{\infty} F\left(T_{i}\right)$. If $\mathcal{F}$ is a nonempty-bounded subset in $C$, then $\left\{x_{n}\right\}$ converges strongly to $\Pi_{\mp} x_{1}$.

Proof. We divide the proof of Theorem 2.1 into five steps.

(I) $F$ and $C_{n}, n \geq 1$ are closed and convex subset in $C$. 
In fact, it follows from Lemma 1.6 that $F\left(T_{i}\right), i \geq 1$ is closed and convex subset of $C$. Therefore $\mathcal{F}$ is a closed and convex subset in $C$.

Again by the assumption that $C_{1}=C$ is closed and convex. Suppose that $C_{n}$ is closed and convex for some $n \geq 2$. In view of the definition of $\phi$ we have that

$$
\begin{aligned}
C_{n+1}= & \left\{z \in C_{n}: \sup _{i \geq 1} \phi\left(z, y_{n, i}\right) \leq \alpha_{n} \phi\left(z, x_{1}\right)+\left(1-\alpha_{n}\right) \phi\left(z, x_{n}\right)+\theta_{n}\right\} \\
= & \bigcap_{i \geq 1}\left\{z \in C_{n}: \phi\left(z, y_{n, i}\right) \leq \alpha_{n} \phi\left(z, x_{1}\right)+\left(1-\alpha_{n}\right) \phi\left(z, x_{n}\right)+\theta_{n}\right\} \cap C_{n} \\
= & \bigcap_{i \geq 1}\left\{z \in C_{n}: 2 \alpha_{n}\left\langle z, J x_{1}\right\rangle+2\left(1-\alpha_{n}\right)\left\langle z, J x_{n}\right\rangle-2\left\langle z, J y_{n, i}\right\rangle\right. \\
& \left.\leq \alpha_{n}\left\|x_{1}\right\|^{2}+\left(1-\alpha_{n}\right)\left\|x_{n}\right\|^{2}-\left\|y_{n, i}\right\|^{2}+\theta_{n}\right\} \cap C_{n} .
\end{aligned}
$$

This implies that $C_{n+1}$ is closed and convex. The conclusion is proved.

(II) Now we prove that $\mathcal{F} \subset C_{n}, n \geq 1$.

In fact, it is obvious that $\mathcal{F} \subset C_{1}=C$. Suppose that $\mathscr{F} \subset C_{n}$ for some $n \geq 2$. Letting

$$
w_{n, i}=J^{-1}\left(\beta_{n} J x_{n}+\left(1-\beta_{n}\right) J T_{i}\left(P T_{i}\right)^{n-1} x_{n}\right),
$$

it follows from (1.6) that for any $u \in \mathcal{F} \subset C_{n}$ we have

$$
\begin{aligned}
\phi\left(u, y_{n, i}\right) & =\phi\left(u, J^{-1}\left(\alpha_{n} J x_{1}+\left(1-\alpha_{n}\right) J w_{n, i}\right)\right) \\
& \leq \alpha_{n} \phi\left(u, x_{1}\right)+\left(1-\alpha_{n}\right) \phi\left(u, w_{n, i}\right), \\
\phi\left(u, w_{n, i}\right) & =\phi\left(u, J^{-1}\left(\beta_{n} J x_{n}+\left(1-\beta_{n}\right) J T_{i}\left(P T_{i}\right)^{n-1} x_{n}\right)\right) \\
& \leq \beta_{n} \phi\left(u, x_{n}\right)+\left(1-\beta_{n}\right) \phi\left(u, T_{i}\left(P T_{i}\right)^{n-1} x_{n}\right) \\
& \leq \beta_{n} \phi\left(u, x_{n}\right)+\left(1-\beta_{n}\right)\left\{\phi\left(u, x_{n}\right)+v_{n} \rho\left(\phi\left(u, x_{n}\right)\right)+\mu_{n}\right\} \\
& =\phi\left(u, x_{n}\right)+\left(1-\beta_{n}\right)\left(v_{n} \rho\left(\phi\left(u, x_{n}\right)\right)+\mu_{n}\right) \\
& \leq \phi\left(u, x_{n}\right)+v_{n} \rho\left(\phi\left(u, x_{n}\right)\right)+\mu_{n},
\end{aligned}
$$

therefore we have

$$
\begin{aligned}
\sup _{i \geq 1} \phi\left(u, y_{n, i}\right) & \leq \alpha_{n} \phi\left(u, x_{1}\right)+\left(1-\alpha_{n}\right)\left\{\phi\left(u, x_{n}\right)+v_{n} \rho\left(\phi\left(u, x_{n}\right)\right)+\mu_{n}\right\} \\
& \leq \alpha_{n} \phi\left(u, x_{1}\right)+\left(1-\alpha_{n}\right) \phi\left(u, x_{n}\right)+v_{n} \sup _{u \in \mathscr{F}} \rho\left(\phi\left(u, x_{n}\right)\right)+\mu_{n} \\
& \leq \alpha_{n} \phi\left(u, x_{1}\right)+\left(1-\alpha_{n}\right) \phi\left(u, x_{n}\right)+\theta_{n},
\end{aligned}
$$


where $\theta_{n}=v_{n} \sup _{u \in \mathcal{F}} \rho\left(\phi\left(u, x_{n}\right)\right)+\mu_{n}$. This shows that $u \in C_{n+1}$, and so $\mathcal{F} \subset C_{n+1}$. The conclusion is proved.

(III) Next we prove that $\left\{x_{n}\right\}$ is a Cauchy sequence in $C$.

In fact, since $x_{n}=\Pi_{C_{n}} x_{1}$, from Lemma 1.1(2) we have

$$
\left\langle x_{n}-y_{,} J x_{1}-J x_{n}\right\rangle \geq 0, \quad \forall y \in C_{n} .
$$

Again since $\mathcal{F} \subset C_{n}$, for all $n \geq 1$, we have

$$
\left\langle x_{n}-u, J x_{1}-J x_{n}\right\rangle \geq 0, \quad \forall u \in \mathcal{F} .
$$

It follows from Lemma 1.1(1) that for each $u \in \mathcal{F}$ and for each $n \geq 1$

$$
\phi\left(x_{n}, x_{1}\right)=\phi\left(\Pi_{C_{n}} x_{1}, x_{1}\right) \leq \phi\left(u, x_{1}\right)-\phi\left(u, x_{n}\right) \leq \phi\left(u, x_{1}\right)
$$

Therefore $\left\{\phi\left(x_{n}, x_{1}\right)\right\}$ is bounded. By virtue of (1.5), $\left\{x_{n}\right\}$ is also bounded.

Since $x_{n}=\Pi_{C_{n}} x_{1}$ and $x_{n+1}=\Pi_{C_{n+1}} x_{1} \in C_{n+1} \subset C_{n}$, we have $\phi\left(x_{n}, x_{1}\right) \leq \phi\left(x_{n+1}, x_{1}\right)$, for all $n \geq 1$. This implies that $\left\{\phi\left(x_{n}, x_{1}\right)\right\}$ is nondecreasing. Hence the $\operatorname{limit}_{n \rightarrow \infty} \lim _{n \rightarrow \infty} \phi\left(x_{n}, x_{1}\right)$ exists. By the construction of $C_{n}$, for any positive integer $m \geq n$, we have $C_{m} \subset C_{n}$ and $x_{m}=\Pi_{C_{m}} x_{1} \in C_{n}$. This shows that

$$
\phi\left(x_{m}, x_{n}\right)=\phi\left(x_{m}, \Pi_{C_{n}} x_{1}\right) \leq \phi\left(x_{m}, x_{1}\right)-\phi\left(x_{n}, x_{1}\right) \longrightarrow 0, \quad \text { as } n, m \longrightarrow \infty .
$$

It follows from Lemma 1.5 that $\lim _{m, n \rightarrow \infty}\left\|x_{m}-x_{n}\right\|=0$. Hence $\left\{x_{n}\right\}$ is a Cauchy sequence in $C$. Since $C$ is a nonempty closed subset of Banach space $E$, it is complete, without loss of generality, we can assume that $x_{n} \rightarrow x^{*}(n \rightarrow \infty)$.

By the assumption, it is easy to see that

$$
\lim _{n \rightarrow \infty} \theta_{n}=\lim _{n \rightarrow \infty}\left(v_{n} \sup _{u \in \mathcal{F}} \rho\left(\phi\left(u, x_{n}\right)\right)+\mu_{n}\right)=0 .
$$

(IV) Now we prove that $x^{*} \in \mathcal{F}$.

In fact, since $x_{n+1} \in C_{n+1}$ and $\alpha_{n} \rightarrow 0$, it follows from (2.1) and (2.11) that

$$
\sup _{i \geq 1} \phi\left(x_{n+1}, y_{n, i}\right) \leq \alpha_{n} \phi\left(x_{n+1}, x_{1}\right)+\left(1-\alpha_{n}\right) \phi\left(x_{n+1}, x_{n}\right)+\theta_{n} \longrightarrow 0 \quad(\text { as } n \longrightarrow \infty)
$$

Since $x_{n} \rightarrow x^{*}$, by virtue of Lemma 1.5 for each $i \geq 1$, we have

$$
\lim _{n \rightarrow \infty} y_{n, i}=x^{*}
$$

Since $\left\{x_{n}\right\}$ is bounded, $\left\{T_{i}\right\}_{i=1}^{\infty}$ is uniformly total quasi- $\phi$-asymptotically nonexpansive nonself mappings with nonnegative real sequence $\left\{v_{n}\right\},\left\{\mu_{n}\right\}$ and a strictly increasing continuous 
function $\rho: \mathbb{R}^{+} \rightarrow \mathcal{R}^{+}$such that $v_{n} \rightarrow 0, \mu_{n} \rightarrow 0$, and $\rho(0)=0$, for any given $u \in \mathcal{F}$, we have

$$
\phi\left(u, T_{i}\left(P T_{i}\right)^{n-1} x_{n}\right) \leq \phi\left(u, x_{n}\right)+v_{n} \rho\left(\phi\left(u, x_{n}\right)\right)+\mu_{n}
$$

This implies that $\left\{T_{i}\left(P T_{i}\right)^{n-1} x_{n}\right\}$ is uniformly bounded. Since

$$
\begin{aligned}
\left\|w_{n, i}\right\| & =\left\|J^{-1}\left(\beta_{n} J x_{n}+\left(1-\beta_{n}\right) J T_{i}\left(P T_{i}\right)^{n-1} x_{n}\right)\right\| \\
& \leq \beta_{n}\left\|x_{n}\right\|+\left(1-\beta_{n}\right)\left\|T_{i}\right\| P T_{i}\left\|^{n-1} x_{n}\right\| \\
& \leq\left\|x_{n}\right\|+\left\|T_{i}\left(P T_{i}\right)^{n-1} x_{n}\right\| .
\end{aligned}
$$

This implies that $\left\{w_{n, i}\right\}$ is also uniformly bounded.

Since $\alpha_{n} \rightarrow 0$, from (2.1), for each $i \geq 1$ we have

$$
\lim _{n \rightarrow \infty}\left\|J y_{n, i}-J w_{n, i}\right\|=\lim _{n \rightarrow \infty} \alpha_{n}\left\|J x_{1}-J w_{n, i}\right\|=0
$$

Since $J^{-1}$ is uniformly continuous on each bounded subset of $E^{*}$, it follows from (2.13) and (2.16) that

$$
\lim _{n \rightarrow \infty} w_{n, i}=x^{*} \quad \text { for each } i \geq 1 \text {. }
$$

Since $J$ is uniformly continuous on each bounded subset of $E$, we have

$$
\begin{aligned}
0 & =\lim _{n \rightarrow \infty}\left\|J w_{n, i}-J x^{*}\right\| \\
& =\lim _{n \rightarrow \infty}\left\|\beta_{n} J x_{n}+\left(1-\beta_{n}\right) J T_{i}\left(P T_{i}\right)^{n-1} x_{n}-J x^{*}\right\| \\
& =\lim _{n \rightarrow \infty}\left\|\beta_{n}\left(J x_{n}-J x^{*}\right)+\left(1-\beta_{n}\right)\left(J T_{i}\left(P T_{i}\right)^{n-1} x_{n}-J x^{*}\right)\right\| \\
& =\lim _{n \rightarrow \infty}\left(1-\beta_{n}\right)\left\|J T_{i}\left(P T_{i}\right)^{n-1} x_{n}-J x^{*}\right\| .
\end{aligned}
$$

By condition (b), we have that

$$
\lim _{n \rightarrow \infty}\left\|J T_{i}\left(P T_{i}\right)^{n-1} x_{n}-J x^{*}\right\|=0
$$

Since $J$ is uniformly continuous, this shows that $\lim _{n \rightarrow \infty} T_{i}\left(P T_{i}\right)^{n-1} x_{n}=x^{*}$ uniformly in $i \geq 1$. 
Again by the assumptions that for each $i \geq 1, T_{i}$ is uniformly $L_{i}$-Lipschitz continuous, thus we have

$$
\begin{aligned}
&\left\|T_{i}\left(P T_{i}\right)^{n} x_{n}-T_{i}\left(P T_{i}\right)^{n-1} x_{n}\right\| \\
& \quad \leq\left\|T_{i}\left(P T_{i}\right)^{n} x_{n}-T_{i}\left(P T_{i}\right)^{n} x_{n+1}\right\|+\left\|T_{i}\left(P T_{i}\right)^{n} x_{n+1}-x_{n+1}\right\| \\
& \quad+\left\|x_{n+1}-x_{n}\right\|+\left\|x_{n}-T_{i}\left(P T_{i}\right)^{n-1} x_{n}\right\| \\
& \leq\left(L_{i}+1\right)\left\|x_{n}-x_{n+1}\right\|+\left\|T_{i}\left(P T_{i}\right)^{n} x_{n+1}-x_{n+1}\right\|+\left\|x_{n}-T_{i}\left(P T_{i}\right)^{n-1} x_{n}\right\| .
\end{aligned}
$$

Since $\lim _{n \rightarrow \infty} T_{i}\left(P T_{i}\right)^{n-1} x_{n}=x^{*}$ and $x_{n} \rightarrow x^{*}$, these together with (2.20) imply that $\lim _{n \rightarrow \infty}\left\|T_{i}\left(P T_{i}\right)^{n} x_{n}-T_{i}\left(P T_{i}\right)^{n-1} x_{n}\right\|=0$ and $\lim _{n \rightarrow \infty} T_{i}\left(P T_{i}\right)^{n} x_{n}=x^{*}$, that is,

$$
\lim _{n \rightarrow \infty} T_{i} P\left(P T_{i}\right)^{n-1} x_{n}=x^{*}
$$

In view continuity of $T_{i} P$, it yields that $T_{i} P x^{*}=x^{*}$. Since $x^{*} \in C, P x^{*}=x^{*}$. This shows that $T x^{*}=x^{*}$. By the arbitrariness of $i \geq 1$, we have $x^{*} \in \mathcal{F}$.

(V) Finally we prove that $x_{n} \rightarrow x^{*}=\prod_{\mp} x_{1}$.

Let $w=\Pi_{\mathcal{F}} x_{1}$. Since $w \in \mathcal{F} \subset C_{n}$ and $x_{n}=\Pi_{C_{n}} x_{1}$, we have $\phi\left(x_{n}, x_{1}\right) \leq \phi\left(w, x_{1}\right)$, for all $n \geq 1$. This implies that

$$
\phi\left(x^{*}, x_{1}\right)=\lim _{n \rightarrow \infty} \phi\left(x_{n}, x_{1}\right) \leq \phi\left(w, x_{1}\right)
$$

In view of the definition of $\Pi_{\mp} x_{1}$, from (2.22) we have $x^{*}=w$. Therefore $x_{n} \rightarrow x^{*}=\Pi_{\mp} x_{1}$. This completes the proof of Theorem 2.1.

Theorem 2.2. Let $E, C,\left\{\alpha_{n}\right\},\left\{\beta_{n}\right\}$ be the same as in Theorem 2.1. Let $T_{i}: C \rightarrow E, i=1,2, \ldots$ be a family of closed and uniformly quasi- $\phi$-asymptotically nonexpansive nonself mappings with sequence $\left\{k_{n}\right\} \subset[1, \infty), k_{n} \rightarrow 1$, and for each $i \geq 1, T_{i}$ be uniformly $L_{i}$-Lipschitz continuous. Let $\left\{x_{n}\right\}$ be a sequence generated by

$$
\begin{gathered}
x_{1} \in E \text { chosen arbitrarily; } C_{1}=C, \\
y_{n, i}=J^{-1}\left[\alpha_{n} J x_{1}+\left(1-\alpha_{n}\right)\left(\beta_{n} J x_{n}+\left(1-\beta_{n}\right) J T_{i}\left(P T_{i}\right)^{n-1} x_{n}\right)\right], \quad i \geq 1, \\
C_{n+1}=\left\{z \in C_{n}: \sup _{i \geq 1} \phi\left(z, y_{n, i}\right) \leq \alpha_{n} \phi\left(z, x_{1}\right)+\left(1-\alpha_{n}\right) \phi\left(z, x_{n}\right)+\theta_{n}\right\}, \\
x_{n+1}=\prod_{C_{n+1}} x_{1}, \quad \forall n \geq 1,
\end{gathered}
$$

where $\theta_{n}=\left(k_{n}-1\right) \sup _{u \in \mathcal{F}} \phi\left(u, x_{n}\right), \mathcal{F}:=\bigcap_{i=1}^{\infty} F\left(T_{i}\right)$. If $\mathcal{F}$ is a nonempty bounded subset in $C$, then $\left\{x_{n}\right\}$ converges strongly to $\Pi_{\mp} x_{1}$.

Proof. By Remark $1.4 T_{i}: C \rightarrow E, i=1,2, \ldots$ be a family of closed and uniformly quasi$\phi$-asymptotically nonexpansive nonself mappings that it is a family of closed and uniformly 
total quasi- $\phi$-asymptotically nonexpansive nonself mappings with taking $\rho(t)=t, t>0$, $v_{n}=\left(k_{n}-1\right)$ and $\mu_{n}=0$. Therefore all conditions in Theorem 2.1 are satisfied. By the similar methods as given in the proof of Theorem 2.1, we can prove that the sequence $\left\{x_{n}\right\}$ defined by $(2.23)$ converges strongly to $\Pi_{\mp} x_{1}$.

Theorem 2.3. Let $E, C,\left\{\alpha_{n}\right\},\left\{\beta_{n}\right\}$ be the same as in Theorem 2.2. Let $T_{i}: C \rightarrow E, i=1,2, \ldots$ be a family of quasi- $\phi$-nonexpansive nonself mappings such that $\mathcal{F}:=\bigcap_{i=1}^{\infty} F\left(T_{i}\right) \neq \emptyset$ and for each $i \geq 1, T_{i}$ be uniformly $L_{i}$-Lipschitz continuous. Let $\left\{x_{n}\right\}$ be a sequence generated by

$$
\begin{gathered}
x_{1} \in E \text { chosen arbitrarily; } C_{1}=C, \\
y_{n, i}=J^{-1}\left[\alpha_{n} J x_{1}+\left(1-\alpha_{n}\right)\left(\beta_{n} J x_{n}+\left(1-\beta_{n}\right) J T_{i} x_{n}\right)\right], \quad i \geq 1, \\
C_{n+1}=\left\{z \in C_{n}: \sup _{i \geq 1} \phi\left(z, y_{n, i}\right) \leq \alpha_{n} \phi\left(z, x_{1}\right)+\left(1-\alpha_{n}\right) \phi\left(z, x_{n}\right)\right\}, \\
x_{n+1}=\prod_{C_{n+1}} x_{1}, \quad \forall n \geq 1 .
\end{gathered}
$$

Then $\left\{x_{n}\right\}$ converges strongly to $\Pi_{\mp} x_{1}$.

Proof. By Remark 1.4 $T_{i}: C \rightarrow E, i=1,2, \ldots$ be a family of quasi- $\phi$-nonexpansive nonself mappings that it is a family of uniformly quasi- $\phi$-asymptotically nonexpansive nonself mappings with sequence $\left\{k_{n}\right\}=\{1\}$. Hence $\theta_{n}=\left(k_{n}-1\right) \sup _{u \in \mathcal{F}} \phi\left(u, x_{n}\right)=0$ Therefore all conditions in Theorem 2.2 are satisfied. By the similar methods, we can prove that the sequence $\left\{x_{n}\right\}$ defined by (2.24) converges strongly to $\Pi_{\mp} x_{1}$.

\section{Application and Example}

In this section we utilize the results presented in Section 2 to prove a strong convergence theorem concerning maximal monotone operators in Hilbert spaces.

Let $E$ be a real Hilbert space and let $A$ be a maximal monotone operator from $E$ to $E$. For each $r>0$, we can define a single valued mapping $J_{r}^{A}: E \rightarrow E$ by $J_{r}^{A}=(I+r A)^{-1}$ and such a mapping $J_{r}^{A}$ is called the resolvent of $A$. It is easy to prove that $J_{r}^{A}$ is a nonexpansive mapping and $A^{-1}(0)=F\left(J_{r}^{A}\right)$ for all $r>0$. Therefore it is a uniformly 1-Lipschitz continuous and quasi- $\phi$-nonexpansive mapping. Hence for each $p \in F\left(J_{r}^{A}\right)$ and $w \in E$, we have

$$
\phi\left(p, J_{r}^{A} w\right) \leq \phi(p, w)
$$

and $F\left(J_{r}^{A}\right)=A^{-1}(0)$. These show that all conditions in Theorem 2.3 are satisfied. Hence from Theorem 2.3 we have the following. 
Theorem 3.1. Let $E$ be a real Hilbert space. Let $A_{1}, A_{2}$ be two maximal monotone operators from $E$ to $E$ such that $\mp=A_{1}^{-1}(0) \cap A_{2}^{-1}(0) \neq \emptyset$. Let $J_{r}^{A_{1}}$ and $J_{r}^{A_{2}}$ be the resolvent of $A_{1}$ and $A_{2}$, respectively, where $r>0$. Let $\left\{\alpha_{n}\right\},\left\{\beta_{n}\right\}$ be the same as in Theorem 2.3 and $\left\{x_{n}\right\}$ be the sequence defined by

$$
\begin{gathered}
x_{1} \in E \text { chosen arbitrarily; } C_{1}=E, \\
y_{n, i}=J^{-1}\left[\alpha_{n} J x_{1}+\left(1-\alpha_{n}\right)\left(\beta_{n} J x_{n}+\left(1-\beta_{n}\right) J J_{r}^{A_{i}} x_{n}\right)\right], \quad i=1,2, \\
C_{n+1}=\left\{z \in C_{n}: \max _{i=1,2} \phi\left(z, y_{n, i}\right) \leq \alpha_{n} \phi\left(z, x_{1}\right)+\left(1-\alpha_{n}\right) \phi\left(z, x_{n}\right)\right\}, \\
x_{n+1}=P_{C_{n+1}} x_{1}, \quad \forall n \geq 1,
\end{gathered}
$$

where $P_{C}$ is the metric projection from $H$ onto the subset $C \subset H$. Then the sequence $\left\{x_{n}\right\}$ defined by (3.2) converges strongly to $P_{\mp} x_{1}$.

\section{Acknowledgments}

The authors would like to express their thanks to the referees and the Editor for their helpful comments and suggestions. This Project was supported by the Scientific Research Fund of SiChuan Provincial Education Department (no. 11ZA222).

\section{References}

[1] Y. I. Alber, "Metric and generalized projection operators in Banach spaces: properties and applications," in Theory and Applications of Nonlinear Operators of Accretive and Monotone Type, A. G. Kartosator, Ed., pp. 15-50, Marcel Dekker, New York, NY, USA, 1996.

[2] W. Nilsrakoo and S. Saejung, "Strong convergence theorems by Halpern-Mann iterations for relatively nonexpansive mappings in Banach spaces," Applied Mathematics and Computation, vol. 217, no. 14, pp. 6577-6586, 2011.

[3] C. E. Chidume, E. U. Ofoedu, and H. Zegeye, "Strong and weak convergence theorems for asymptotically nonexpansive mappings," Journal of Mathematical Analysis and Applications, vol. 280, no. 2, pp. 364-374, 2003.

[4] S. S. Chang, C. K. Chan, and H. W. Joseph Lee, "Modified block iterative algorithm for quasi$\phi$-asymptotically nonexpansive mappings and equilibrium problem in Banach spaces," Applied Mathematics and Computation, vol. 217, no. 18, pp. 7520-7530, 2011.

[5] S. S. Chang, H. W. Joseph Lee, and C. K. Chan, "A new hybrid method for solving a generalized equilibrium problem, solving a variational inequality problem and obtaining common fixed points in Banach spaces, with applications," Nonlinear Analysis, vol. 73, no. 7, pp. 2260-2270, 2010.

[6] S. S. Chang, H. W. Joseph Lee, C. K. Chan, and L. Yang, "Approximation theorems for total quasi- $\phi$ asymptotically nonexpansive mappings with applications," Applied Mathematics and Computation, vol. 218, no. 6, pp. 2921-2931, 2011.

[7] S. S. Chang, L. Wang, Y. K. Tang, B. Wang, and L. J. Qin, "Strong convergence theorems for a countable family of quasi- $\phi$-asymptotically nonexpansive nonself mappings," Applied Mathematics and Computation, vol. 218, no. 15, pp. 7864-7870, 2012.

[8] W. P. Guo and W. Guo, "Weak convergence theorems for asymptotically nonexpansive nonselfmappings," Applied Mathematics Letters, vol. 24, no. 12, pp. 2181-2185, 2011.

[9] Y. Hao, S. Y. Cho, and X. Qin, "Some weak convergence theorems for a family of asymptotically nonexpansive nonself mappings," Fixed Point Theory and Applications, Article ID 218573, 11 pages, 2010.

[10] S. Kamimura and W. Takahashi, "Strong convergence of a proximal-type algorithm in a Banach space," SIAM Journal on Optimization, vol. 13, no. 3, pp. 938-945, 2002. 
[11] H. Kiziltunc and S. Temir, "Convergence theorems by a new iteration process for a finite family of nonself asymptotically nonexpansive mappings with errors in Banach spaces," Computers $\mathcal{E}$ Mathematics with Applications, vol. 61, no. 9, pp. 2480-2489, 2011.

[12] H. K. Pathak, Y. J. Cho, and S. M. Kang, "Strong and weak convergence theorems for nonselfasymptotically perturbed nonexpansive mappings," Nonlinear Analysis, vol. 70, no. 5, pp. 1929-1938, 2009.

[13] X. Qin, S. Y. Cho, T. Wang, and S. M. Kang, "Convergence of an implicit iterative process for asymptotically pseudocontractive nonself-mappings," Nonlinear Analysis, vol. 74, no. 17, pp. 58515862, 2011.

[14] Y. F. Su, H. K. Xu, and X. Zhang, "Strong convergence theorems for two countable families of weak relatively nonexpansive mappings and applications," Nonlinear Analysis, vol. 73, no. 12, pp. 38903906, 2010.

[15] S. Thianwan, "Common fixed points of new iterations for two asymptotically nonexpansive nonselfmappings in a Banach space," Journal of Computational and Applied Mathematics, vol. 224, no. 2, pp. 688-695, 2009.

[16] Z. M. Wang, Y. F. Su, D. X. Wang, and Y. C. Dong, "A modified Halpern-type iteration algorithm for a family of hemi-relatively nonexpansive mappings and systems of equilibrium problems in Banach spaces," Journal of Computational and Applied Mathematics, vol. 235, no. 8, pp. 2364-2371, 2011.

[17] I. Yıldırım and M. Özdemir, "A new iterative process for common fixed points of finite families of non-self-asymptotically non-expansive mappings," Nonlinear Analysis, vol. 71, no. 3-4, pp. 991-999, 2009.

[18] L. P. Yang and X. S. Xie, "Weak and strong convergence theorems of three step iteration process with errors for nonself-asymptotically nonexpansive mappings," Mathematical and Computer Modelling, vol. 52, no. 5-6, pp. 772-780, 2010.

[19] H. Zegeye, E. U. Ofoedu, and N. Shahzad, "Convergence theorems for equilibrium problem, variational inequality problem and countably infinite relatively quasi-nonexpansive mappings," Applied Mathematics and Computation, vol. 216, no. 12, pp. 3439-3449, 2010.

[20] P. Kanjanasamranwong, P. Kumam, and S. Saewan, "A modified Halpern type iterative method of a system of equilibrium problems and a fixed point for a totally quasi-phi-asymptotically non expansive mapping in a Banach space," Journal of Applied Mathematics, vol. 2012, Article ID 750732, 19 pages, 2012.

[21] S. Saewan and P. Kumam, "A strong convergence theorem concerning a hybrid projection method for finding common fixed points of a countable family of relatively quasi-nonexpansive mappings," Journal of Nonlinear and Convex Analysis, vol. 13, no. 2, pp. 313-330, 2012.

[22] S. Saewan and P. Kumam, "Convergence theorems for mixed equilibrium problems, variational inequality problem and uniformly quasi- $\phi$-asymptotically nonexpansive mappings," Applied Mathematics and Computation, vol. 218, no. 7, pp. 3522-3538, 2011.

[23] S. Saewan and P. Kumam, "Convergence theorems for uniformly quasi- $\phi$ - asymptotically nonexpansive mappings, generalized equilibrium problems and variational inequalities," Journal of Inequalities and Applications, vol. 2011, article 96, 2011.

[24] S. Saewan and P. Kumam, "A new modified block iterative algorithm for uniformly quasi- $\phi$ asymptotically nonexpansive mappings and a system of generalized mixed equilibrium problems," Fixed Point Theory and Applications, vol. 2011, article 35, 2011.

[25] K. Wattanawitoon and P. Kumam, "The modified block iterative algorithms for asymptotically relatively nonexpansive mappings and the system of generalized mixed equilibrium problems," Journal of Applied Mathematics, vol. 2012, Article ID 395760, 24 pages, 2012. 


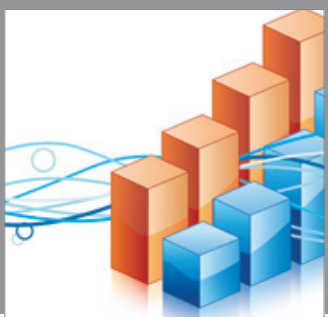

Advances in

Operations Research

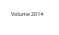

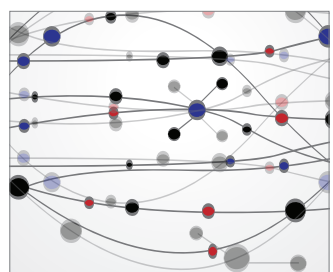

\section{The Scientific} World Journal
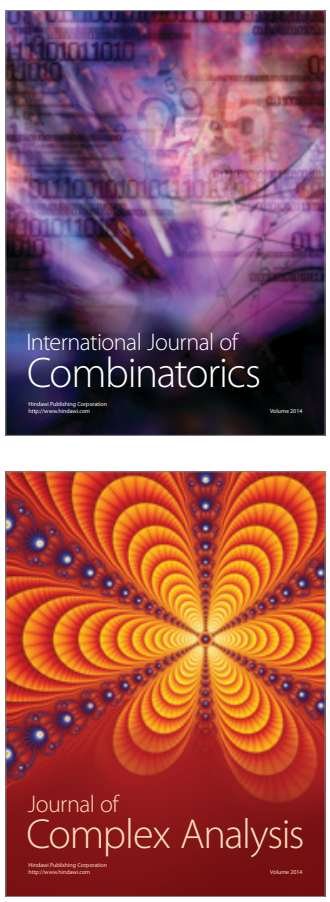

International Journal of

Mathematics and

Mathematical

Sciences
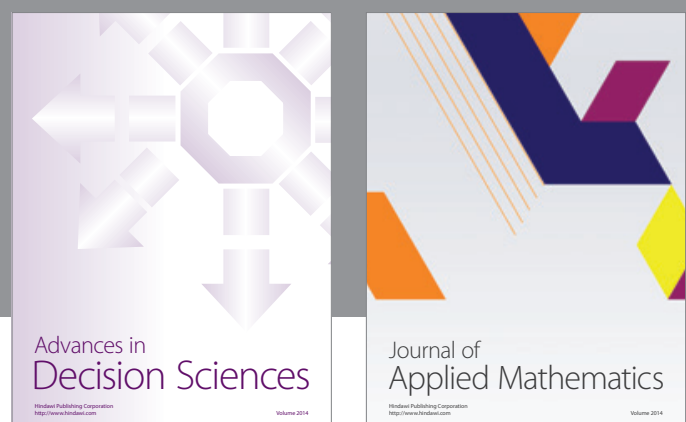

Journal of

Applied Mathematics
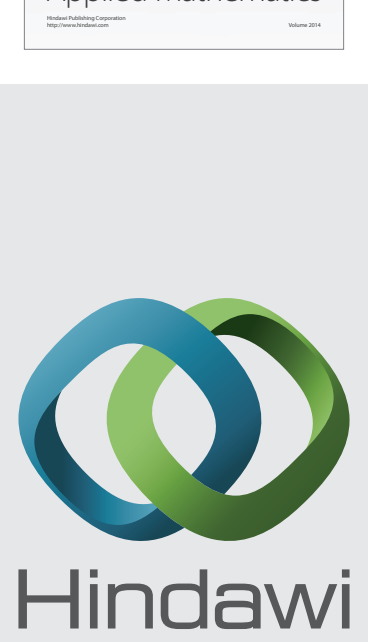

Submit your manuscripts at http://www.hindawi.com
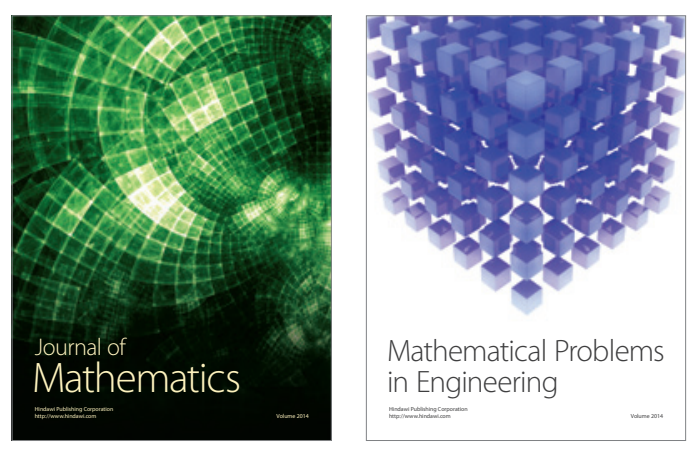

Mathematical Problems in Engineering
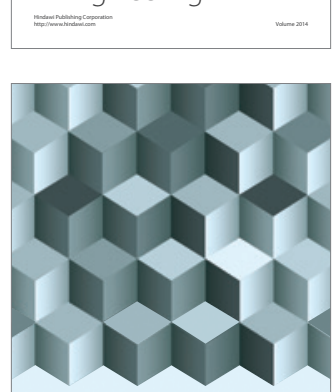

Journal of

Function Spaces
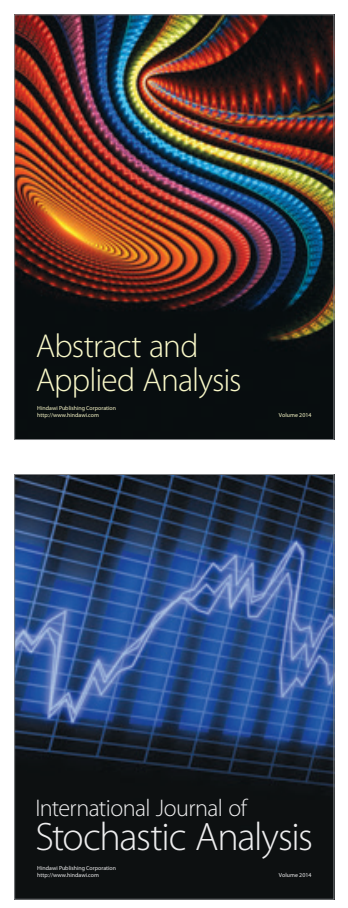

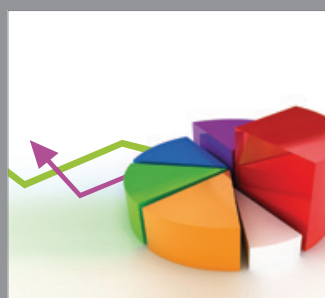

ournal of

Probability and Statistics

Promensencen
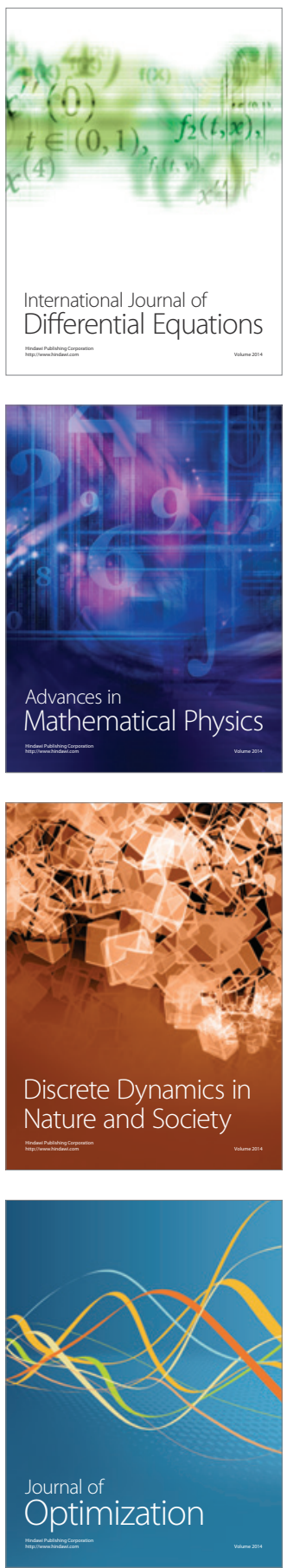